\title{
A Nested Qualitative Evaluation of User Experiences in a Randomized Trial of a Digital Intervention To Support Total-Skin-Self-Examination By Melanoma Survivors
}

\author{
Felicity Reilly \\ University of Aberdeen \\ Nuha Wani \\ University of Aberdeen \\ Susan Hall \\ University of Aberdeen \\ Heather Morgan \\ University of Aberdeen \\ Julia Allan \\ University of Aberdeen \\ Peter Murchie ( $\sim$ p.murchie@abdn.ac.uk) \\ University of Aberdeen \\ Lynda Constable \\ University of Aberdeen
}

\section{Research Article}

Keywords: Mobile applications, melanoma, early detection of cancer, qualitative interviews, cancer survivorship

Posted Date: October 1st, 2021

DOl: https://doi.org/10.21203/rs.3.rs-847522/v1

License: (c) (1) This work is licensed under a Creative Commons Attribution 4.0 International License. Read Full License 


\section{Abstract}

\section{Background}

Melanoma is a common cancer with a high survival rate, as well as a high chance of recurrence. Combined, this leads to a high burden of follow-up. Total-Skin-Self-Examination (TSSE) improves clinical outcomes of melanoma via early detection of new primaries and recurrences, and technology is an increasingly popular means of facilitating TSSE. Thus, the Achieving Self-directed Integrated Cancer Aftercare (ASICA) digital healthcare intervention was developed. Embedded within a randomised control trial (RCT), this nested study used qualitative interviews to explore in depth participants' experiences of TSSE, their orientation toward technology and both participant and professionals' practical and technical experiences of the ASICA intervention.

\section{Methods}

Semi-structured telephone interviews were undertaken during the RCT with participants and the coordinating Dermatology Nurse Practitioner (DNP). Participants were purposively sampled to achieve a representative sample. Interviews were transcribed verbatim and analysed using a Framework Analysis approach applied within NVivo12.

\section{Results}

Twenty-two interviews were completed with participants and one with the coordinating DNP. ASICA appeared to change participants' perceptions of skin checking: users were more likely to report routinely performing TSSE thoroughly. There was some variation in beliefs about skin-checking and using technology for healthcare generally. Overall, ASICA was experienced positively by participants and the DNP. Several clear practical suggestions were made for how ASICA can be improved.

\section{Conclusion}

The ASICA app appears to have positively influenced the attitudes and TSSE practices of melanoma survivors. Technical improvements are required, but the app offers promise for technologically enhanced melanoma follow-up in future.

\section{Trial Registration}

Clinical Trials.gov, NCT03328247. Registered on 1 November 2017 -

https://clinicaltrials.gov/ct2/show/NCT03328247?term=ASICA\&rank=1

\section{Introduction}

Melanoma is a cancer of the melanocyte or pigment cell of the skin. It is the fifth most common cancer in the UK, with over 16,000 diagnoses each year.[1, 2] Melanoma's mortality accounts for $1 \%$ of all cancer 
deaths in the UK, equalling 2300 deaths yearly.[2 Although melanoma can be deadly, the relative survival rate at five years is high: almost $90 \%$ in Scotland with equivalent rates across the UK.[3] Once treated, there is a high chance of recurrence, as well as development of new primary melanoma[4]. Therefore, follow-up of melanoma patients is very important. The high chance of recurrence combined with high survival rates leads to a large cohort of patients who require continued surveillance. This has led to patient care post-melanoma becoming burdensome to both health services and patients.[5]

Melanoma follow-up is largely based on regular hospital appointments where patients are physically examined. Additionally, most guidelines recommend that patients should perform Total-Skin-Selfexamination (TSSE) in the intervals between hospital appointments.[6-9]. Studies show that $62 \%$ of melanomas are first identified by patients themselves, with early detection key in improving clinical outcomes. $[9,10]$. It is thought regular TSSE by patients leads to earlier detection of melanoma.[10, 11] The rate of skin checking post-melanoma is similar to the population as a whole however, despite it being widely recommended.[12]

Technology has become commonplace in daily life and is recognised as a potential solution to healthcare challenges, especially in rural areas.[13-15] Qualitative interviews undertaken with melanoma survivors suggest that, with appropriate training and design, smartphone-based app (application) technology offers an acceptable means of promoting TSSE and facilitating delivery of care between routine follow up appointments.[16]

The Achieving Self-directed Integrated Cancer Aftercare (ASICA) intervention aims to prompt, support, record and respond to TSSE conducted by survivors of melanoma and the development has been fully described elsewhere.[16, 17] The intervention is centred around an android app which was operationalized using a 7" tablet computer during the study. The app featured instructional videos informing users how to conduct a structured and sequential TSSE. The app also enabled access to individual digital skin maps to which participants could refer during TSSE and allowed, as well as the ability to send photos of skin lesions detected during TSSE to a Dermatology Nurse Practitioner (DNP). Following development and feasibility testing, ASICA was then subjected to a randomised controlled trial (RCT).[18] The intervention group $(n=121)$ were provided with a tablet incorporating the ASICA app along with receiving standard care, while the control group $(n=120)$ received standard care alone.[18] The ASICA clinical trial aimed to improve participant well-being, improve clinical outcomes and reduce the burden on patients and health services.[18] The effect of ASICA upon participants' well-being, TSSE adherence and on clinical outcomes will be reported elsewhere.

Qualitative studies can complement the quantitative data produced by RCTs by granting detailed insight into how participants have experienced the trial and the intervention.[19] For the ASICA trial, a parallel qualitative process evaluation was conducted to facilitate understanding of how participants and the DNP experienced the ASICA intervention, but also to attempt to explain the change mechanisms underpinning the observed trial outcomes. In this nested study, we aimed to gather information about how the intervention and its underpinning technology could be improved ahead of the next stage of development 
and implementation should ASICA be shown to have a positive impact on patient outcomes. In this embedded qualitative research, interviews were undertaken with a representative sample of participants in the ASICA trial. The first aim of the study was to compare the attitudes, beliefs and TSSE practices of ASICA-users with those in the control group. The second aim of the study was to explore how users of ASICA had experienced the technology and how it had influenced their practice of TSSE. Thirdly, we wanted to know how ASICA users believed the intervention could be improved.

\section{Methods}

\section{Study Design}

This was a qualitative process evaluation embedded within a multi-centre randomised controlled trial (RCT). Semi-structured telephone interviews, guided by a pre-defined topic schedule (Supplementary File S1), were conducted with trial participants in two tranches. Aberdeen participants were interviewed by NW during April 2019.[20] and Cambridge participants by SH in November 2019. FR and PM conducted further semi-structured interview with the DNP in September 2020. The interviews aimed to first, explore the prior experiences of TSSE by trial participants as well as their orientation toward technology, including its role in their healthcare generally, and TSSE specifically. Further, those who had experienced the ASICA intervention, both users and the DNP, were asked about their practical experiences of the intervention and for their views on how it might be improved. The app evaluation questions in the interview schedule were informed by a validated evaluation tool for healthcare apps.[21] However, this instrument was not formally completed by interview subjects, instead it was reproduced on the topic schedule as an aide memoire for the interviewer. The interview with the DNP was pragmatically focussed on his practical experiences of the study, what had worked well and what could be improved in the future.

\section{Sampling Strategy}

The aim was to recruit approximately $10 \%$ of trial participants (intervention and control) up to a maximum of 30 participants across both sites. Purposive sampling was used when inviting participants to ensure acquire multiple viewpoints, representing the demographic range of the participants in the trial. Sampling sought representative proportions by age, sex and residential geography. The pool for potential participants in the parallel qualitative process evaluation was determined from those individuals giving consent to be contacted for a subsequent interview at the point of recruitment. Demographic data were used by NW and PM to construct a sampling framework which was then used to ensure that invitees represented the full range of age, sex and rurality of participants in the trial. We also ensured that we recruited both intervention and control group participants for interview. As participants in the control group had not experienced the ASICA intervention, interviews in these cases focused on their personal experiences of, and orientation toward, monitoring their skin during the study year.

\section{Recruitment}


Eligible participants for interview had: completed 12 months in the ASICA trial; not withdrawn from the trial; and had consented to be contacted for further research. Recruitment was carried out in two tranches as there had been a six-month interval between initiation of the ASICA trial in Aberdeen (March/April 2018) and Cambridge (October/November 2018). Potential interviewees were sent an invitation letter, consent form, and a patient information leaflet describing the qualitative study. Participants who returned signed and correctly completed consent forms were contacted via telephone or email to arrange a suitable time for a call from one of the project interviewers for a telephone interview. All participants were given the opportunity to ask questions and seek further explanation about the qualitative study before going ahead. Recorded verbal consent was obtained prior to starting each interview.

\section{Data Collection}

The first tranche of telephone interviews with Aberdeen participants (intervention and control) were conducted by NW in April 2019. The second tranche of interviews of Cambridge participants were conducted in November 2019 by SH. The sequential geographical interviewing pattern reflecting the fact that recruitment had been completed in Aberdeen sometime before that in Cambridge. The interviews were digitally recorded, anonymised and transcribed verbatim by a professional transcribing service. FR and PM interviewed the ASICA DNP in September 2020, which included a COVID-19 engendered delay.

\section{Data Analysis}

A preliminary thematic analysis was undertaken on a sample of the Aberdeen interviews by NW in May 2019. Subsequently, all completed interviews were analysed together using a Framework approach by FR. [22] Analysis of the full dataset was undertaken between April and July 2020 by FR, HM and PM. Professional transcriptions were uploaded into NVivo12 for analysis.[23] Framework analysis was adopted due to its structured approach and for its utility in applied health research with well-defined questions and structured data, and in enabling comparison between several cases at once.[24] The first analytical step was immersion. FR read and re-read all transcripts in sequence in order to become familiar with the data. This was important as the researcher had not conducted or transcribed the interviews. A third reading was conducted by FR to identify the main themes and subthemes, which were applied to the data and from which FR developed the initial analytical framework which was checked, adapted and agreed by NW and SH. Since the main analysis was completed by FR, who had not conducted the interviews, the decision that data saturation had been reached was not straightforward. FR took the pragmatic view that, since similar themes were repeated in the Aberdeen and Cambridge interviews, the sample size was sufficient to capture the most important issues from the perspective of participants. PM independently read and coded three interviews (an approximate 10\% sample) using the Framework. PM, $\mathrm{HM}$ and FR subsequently discussed and made further minor adjustments and refinements to the Framework. The final Framework is available in Supplementary File S2.

Subsequently, FR systematically applied the coding to each of the interview transcripts in NVivo12. FR then sorted all relevant data into each identified theme and subtheme. Data were then charted and interpreted thematically. Data from different respondents were compared and an overview summarising 
the data from each theme was created. Special consideration was given to the influence of individual demographics on experiences, feelings, opinions and suggestions for improvement. Finally, a full thematically structured narrative account, embedding illustrative quotes was produced by FR, with supervision from PM and HM, and is reproduced below.

The interview with the DNP, which was pragmatically focused, was not analysed formally within the framework of the participant interviews and was instead triangulated with the completed participant analysis to explore context.

\section{Results}

Twenty-two telephone interviews ranging in duration from 10 to 45 minutes were completed and transcribed. The demographics of participating interviewees are summarised in Table 1. Six main themes emerged during coding: skin checking behaviour; friends and family; other health professionals; ideas around technology; 'nuts and bolts'- practical experience of the ASICA trial; and finally, ASICA: the app impact, design and usability. See Supplementary File S2 for full Framework, themes and subthemes. 
Table 1

Demographics of participants in the ASICA interview study

\begin{tabular}{|c|c|c|c|c|c|}
\hline Group & Age & Sex & Urban/Rural* & SIMD/IMD deprivation quintile & Site \\
\hline Intervention & 73 & $\mathrm{~F}$ & Rural & 3 & Grampian \\
\hline Intervention & 47 & $\mathrm{~F}$ & Rural & 3 & Grampian \\
\hline Intervention & 73 & M & Rural & 4 & Grampian \\
\hline Intervention & 54 & $M$ & Rural & 4 & Grampian \\
\hline Intervention & 61 & $M$ & Rural & 4 & Grampian \\
\hline Intervention & 48 & $\mathrm{~F}$ & Rural & 5 & Grampian \\
\hline Intervention & 29 & $M$ & Rural & 4 & Cambridge \\
\hline Intervention & 53 & $\mathrm{~F}$ & Rural & 5 & Cambridge \\
\hline Intervention & 39 & M & Urban & 3 & Grampian \\
\hline Intervention & 60 & $M$ & Urban & 3 & Cambridge \\
\hline Intervention & 86 & $M$ & Urban & 5 & Grampian \\
\hline Intervention & 62 & $\mathrm{~F}$ & Urban & 5 & Grampian \\
\hline Intervention & 60 & $M$ & Urban & 4 & Cambridge \\
\hline Control & 76 & $F$ & Rural & 4 & Grampian \\
\hline Control & 39 & $F$ & Urban & 2 & Cambridge \\
\hline Control & 49 & $M$ & Urban & 5 & Grampian \\
\hline Control & 49 & $F$ & Urban & 5 & Grampian \\
\hline Control & 76 & $M$ & Urban & 5 & Grampian \\
\hline Control & 51 & $M$ & Urban & 5 & Grampian \\
\hline Control & 48 & $\mathrm{~F}$ & Urban & 5 & Grampian \\
\hline Control & 66 & $M$ & Urban & 5 & Grampian \\
\hline Control & 62 & $\mathrm{~F}$ & Urban & 4 & Cambridge \\
\hline \multicolumn{6}{|c|}{ ** 2-Fold Urban Rural status according to Scottish and English Urban Rural Classifications $[25,26]$} \\
\hline
\end{tabular}




\section{How participants in both groups checked their skin during the ASICA trial}

More than three quarters of participants interviewed stated that they examined their skin regularly. Of those who did not, only one was from the ASICA intervention group. Five individuals (three men and two women) reported not checking their skin regularly and it appeared that living alone was a potentially determining factor, not having someone to encourage, remind and help them check awkward or difficult to see areas of the body. Individuals living alone tended to await their regular hospital follow-up appointments feeling that these were sufficient for monitoring their condition. Those who did check their skin regularly mentioned a variety of approaches. The most common method was having an unstructured look over or "quick check'- $(F, 48$, Control). This idea ran through most interviews with participants stating it was part of daily routine to "keep an eye" on things ( $F, 49$ control).

Almost $90 \%$ of the intervention group stated that they used ASICA to aid skin checking, and most reported following the instructions provided which were designed to facilitate a high-quality skin examination.. Two participants in the intervention group stated they no longer used the app to check skin, however one described using what it had taught them initially to continue skin checking using alternative technology. See Table 2.1 for full quote. 
Table 2.1

How participants reported checking their skin

\begin{tabular}{|c|c|c|}
\hline $\begin{array}{l}\text { Analysis } \\
\text { overview }\end{array}$ & Quote & Participant \\
\hline \multirow[t]{2}{*}{$\begin{array}{l}\text { Unstructured } \\
\text { skin checking }\end{array}$} & $\begin{array}{l}\text { "I mean I do keep an eye on it, I don't know if you would class it as } \\
\text { examining" }\end{array}$ & $\begin{array}{l}\text { 11048, } \\
\text { Female, } 48, \\
\text { Control }\end{array}$ \\
\hline & $\begin{array}{l}\text { "I have a quick check to see there's no other strange things happening } \\
\text { and there isn't." }\end{array}$ & $\begin{array}{l}11024, \\
\text { Male, } 76, \\
\text { Control }\end{array}$ \\
\hline \multirow[t]{2}{*}{$\begin{array}{l}\text { Skin } \\
\text { checking with } \\
\text { ASICA app }\end{array}$} & "I just follow it to the app" & $\begin{array}{l}\text { 12048, } \\
\text { Male, } 60 \\
\text { Intervention }\end{array}$ \\
\hline & $\begin{array}{l}\text { "Well I use the app, just look at the pictures and then look at the, look } \\
\text { at the bits on my, bits on my skin, I usually get my husband to look at } \\
\text { my back, backs of my legs and down my back and that" }\end{array}$ & $\begin{array}{l}\text { 11054, } \\
\text { Female, } 47, \\
\text { Intervention }\end{array}$ \\
\hline $\begin{array}{l}\text { Use of other } \\
\text { technology } \\
\text { instead of } \\
\text { ASICA }\end{array}$ & $\begin{array}{l}\text { "the ipad is quite good at taking pictures close up as well, so that's } \\
\text { what we used, I find it a lot easier [than the study tablet], and it moves } \\
\text { a lot easier to touch" }\end{array}$ & $\begin{array}{l}\text { 11060, } \\
\text { Male, 54, } \\
\text { Intervention }\end{array}$ \\
\hline \multirow[t]{2}{*}{$\begin{array}{l}\text { Perceived } \\
\text { thoroughness } \\
\text { of skin } \\
\text { checking }\end{array}$} & $\begin{array}{l}\text { "I don't do is what they suggest you should do which is a thorough } \\
\text { check in every sort of area and, and crack and orifice and under your } \\
\text { boobs and wherever else. So, oh I don't, I don't do that particularly } \\
\text { thoroughly" }\end{array}$ & $\begin{array}{l}\text { 11014, } \\
\text { Female, } 49, \\
\text { Control }\end{array}$ \\
\hline & "I'm not very rigorous about it" & $\begin{array}{l}\text { 12008, } \\
\text { Female, 39, } \\
\text { Control }\end{array}$ \\
\hline
\end{tabular}

\section{When participants checked their skin}

Although there were variations in how people checked their skin, the contexts which checks were conducted in were remarkably consistent. Almost all mentioned checking their skin when they showered, with washing being a near universal prompt. The app users stated that the monthly reminders were a useful prompt to remember to perform a structured skin check. It was not only the intervention group who mentioned the trial triggering them to check skin: a participant in the control group stated that taking part in the trial had influenced her to change her perceptions and personal practice with respect to skin checking. See Table 2.2 for further evidence on when skin checking occurred.

It was generally apparent from interviews that skin checking was widely occurring and valued, and that the thoroughness and effectiveness of checking varied between individuals, among both in those using and not randomised to receive the intervention. However ASICA users appeared more likely to make a conscious effort to check their skin regularly and in a structured way, and around a third stated that they had communicated a concern to the study Clinical Nurse Specialist about using the app. Notably, two 
participants in the control group reported having used technology to digitally enhance their own skin checking and were tracking areas of concern with photos stored on their mobile phones. See Table 2.1 for further detail on how participants checked their skin.

Table 2.2

When participants checked their skin

\begin{tabular}{|lll|}
\hline Analysis overview & Quote & Participant \\
\hline $\begin{array}{l}\text { Showering as a trigger for } \\
\text { skin checking }\end{array}$ & $\begin{array}{l}\text { "If I've had a shower or whatever, I'll sort of look, } \\
\text { does that look different, or does it not" }\end{array}$ & $\begin{array}{l}11054, \text { female, } \\
47, \text { Intervention }\end{array}$ \\
\cline { 2 - 3 } & $\begin{array}{l}\text { "very general check every day, I would say, cause } \\
\text { I'm showering every day." }\end{array}$ & $\begin{array}{l}11014, \text { female, } \\
49, \text { Control }\end{array}$ \\
\hline $\begin{array}{l}\text { App reminder to perform } \\
\text { skin checking }\end{array}$ & $\begin{array}{l}\text { "every month I get a reminder to, to go over it on } \\
\text { the app and check from top to toe" }\end{array}$ & $\begin{array}{l}11062, \text { male, } 61, \\
\text { Intervention }\end{array}$ \\
\hline $\begin{array}{l}\text { Trial participation- } \\
\text { influence on skin } \\
\text { checking }\end{array}$ & $\begin{array}{l}\text { "the questionnaire probably acted as a reminder for } \\
\text { me to do a little bit more," }\end{array}$ & $\begin{array}{l}11014, \text { female, } \\
49, \text { Control }\end{array}$ \\
\hline
\end{tabular}

\section{Knowledge and skills required to perform a skin check}

While all intervention group participants had received training in how to perform a total skin selfexamination as part of the intervention, reports of having receiving training to conduct TSSE in the past as part of usual care varied between individuals and study sites. Overall, four of six Cambridge participants reported having received TSSE training, whereas only three of 14 Grampian participants had received TSSE training. Some participants had skin checking explained and demonstrated to them by a specialist. Just under a quarter of participants reported having received a leaflet explaining TSSE, while several participants reported no knowledge or education about TSSE. See Table 2.3 for quotes on participant experience. 
Table 2.3

Quotes reflecting participants' knowledge and skills about skin checking

\begin{tabular}{|c|c|c|}
\hline $\begin{array}{l}\text { Analysis } \\
\text { overview }\end{array}$ & Quote & Participant \\
\hline \multirow[t]{3}{*}{$\begin{array}{l}\text { Specialist } \\
\text { explanation } \\
\text { of skin } \\
\text { checking }\end{array}$} & $\begin{array}{l}\text { "the doctor had told me, or the consultant told me to look for, you know, } \\
\text { like changes in shape or symmetry or colour, or text, you know, if it got } \\
\text { raised or just that sort of thing, looking for any changes, or anything } \\
\text { new, that wasn't there before." }\end{array}$ & $\begin{array}{l}11054, \\
\text { female, } 47, \\
\text { Intervention }\end{array}$ \\
\hline & $\begin{array}{l}\text { "fairly good instructions, and usually from the nurses more than the } \\
\text { doctors, but on the skin checks I've had through the NHS, they, they've } \\
\text { been quite good in terms of tutorials, so I'm quite happy in terms of } \\
\text { what I'm looking at" }\end{array}$ & $\begin{array}{l}12008, \\
\text { female, } 39, \\
\text { Control }\end{array}$ \\
\hline & "was shown how to do the groin," & $\begin{array}{l}11013, \\
\text { female, } 73 \\
\text { Intervention }\end{array}$ \\
\hline $\begin{array}{l}\text { Leaflet } \\
\text { instruction } \\
\text { for skin } \\
\text { checking }\end{array}$ & $\begin{array}{l}\text { "I'll just have a look, but no, never been told, whatever the, never been } \\
\text { verbally told, there was a leaflet sometime back" }\end{array}$ & $\begin{array}{l}\text { 11040, } \\
\text { male, 51, } \\
\text { Control }\end{array}$ \\
\hline $\begin{array}{l}\text { Self-taught } \\
\text { skin } \\
\text { checking }\end{array}$ & $\begin{array}{l}\text { "I haven't been taught by anybody. I've been doing it for so long, I just } \\
\text { know" }\end{array}$ & $\begin{array}{l}11012, \\
\text { male 49, } \\
\text { Control }\end{array}$ \\
\hline
\end{tabular}

Table 2.4

Quotes reflecting participants' beliefs about skin checking

$\begin{array}{lll}\begin{array}{l}\text { Analysis } \\ \text { overview }\end{array} & \text { Quote Participant }\end{array}$

Skin checking requires input of another person "you can't go and check your own back and stuff, so, so you would need to then have the help of someone else,"

"Hundreds of moles on my skin, so it's not easy to monitor them all together, so that's why I just prefer to speak with the, some kind of professionals, someone like a dermatologist, than just checking myself,"
11052 , female, 48, Control

11018 , male 39, Intervention

11017, female, 76, Control

11060 , male, 54, Intervention
Change in
attitude to skin checking following app use
"I would just say you're, you're far more aware of it, checking your skin and stuff now as what you ever, maybe more so now, than what I was previous" "how do you learn to check your skin, you just look! -11017

Dismissive
attitude to skin checking 
Data on the practice and value of skin checking provided a diverse range of responses from participants with some distinctive threads running through the interviews. Living alone appeared to be the most influential demographic factor, with a practical point being raised that skin checking was very difficult to perform alone, and that help was needed from others to perform it properly. Similarly, participants with many visible moles on their skin reported finding it difficult to adequately monitor them all, preferring a professional to check for changes. The role of others also emerges in a subsequent theme.

The value people placed on skin checking varied between individuals, but some dismissed its value and it appeared to be rarely considered as an active health improvement practice. The relationship between previous melanoma and current health did not appear to be acutely perceived, only one participant mentioning their previous melanoma when asked about their general health. Some participants' opinions on beliefs about skin checking appeared to change after using the ASICA app. See Table 2.4 for further details. Overall, for members of the intervention group, using the ASICA app appeared to increase positive attitudes toward and frequency of practice of TSSE.

\section{Feelings about skin checking}

While it was possible that frequent skin checking could function to increase or heighten worries about melanoma recurrence, there was little evidence within the transcripts that feelings and emotional responses to skin checking were especially powerful. For most, it appeared to be a straightforward and non-emotive practice. Of those who did, some respondents in both the intervention and control groups expressed a lack of confidence in their own ability to correctly self-check and to identify changes which may be indicative of recurrence, suggesting that they saw this as a health professional's role. This view tended to be expressed more by younger respondents. One intervention group participant suggested that before using ASICA, their skin-checking had been an ad-hoc activity to reassure themselves when they became worried about something. Another intervention participant implied that ASICA worked well for them, but only because they were already confident in their ability to skin check. None of the participants stated they felt the need to use the tablet provided for skin checking more regularly than once a month. See Table 2.5 below for further details. 
Table 2.5

Quotes reflecting participants' feelings about skin checking

\begin{tabular}{|c|c|c|}
\hline $\begin{array}{l}\text { Analysis } \\
\text { overview }\end{array}$ & Quote & Participant \\
\hline \multirow{2}{*}{$\begin{array}{l}\text { Lack of } \\
\text { confidence } \\
\text { in skin } \\
\text { checking } \\
\text { ability }\end{array}$} & $\begin{array}{l}\text { "My concern is that the... that was the mole that I was least concerned } \\
\text { about so that, does that makes sense?" }\end{array}$ & $\begin{array}{l}11014, \\
\text { female 49, } \\
\text { Control }\end{array}$ \\
\hline & $\begin{array}{l}\text { "I feel more happier if there's someone told me that, you know, } \\
\text { everything is right with my skin, and that's the words coming from the } \\
\text { specialist, and not me after checking my skin on the app, so you } \\
\text { know." }\end{array}$ & $\begin{array}{l}\text { 11018, } \\
\text { male, 39, } \\
\text { Intervention }\end{array}$ \\
\hline $\begin{array}{l}\text { Use of skin } \\
\text { checking as } \\
\text { reassurance }\end{array}$ & $\begin{array}{l}\text { [before starting using the ASICA app] "I just kind of tended to keep an } \\
\text { eye on things generally, you know, without kind of saying, oh I must do } \\
\text { it this week or whatever, I just do it whenever, whenever it came to } \\
\text { mind, but quite often I would say, because I was kind of worried about } \\
\text { it." }\end{array}$ & $\begin{array}{l}\text { 11054, } \\
\text { female, 47, } \\
\text { Intervention }\end{array}$ \\
\hline
\end{tabular}

\section{Family and friends' input into skin checking}

As outlined above, one of the perceived difficulties with skin checking was that it was difficult to do thoroughly alone. Not all participants received regular help with skin checking, although around three quarters did. Views on the absolute necessity of having assistance varied. Two participants perceived themselves as being unable to complete effective TSSE, particularly when checking their back, without the support of another. In contrast, another two mentioned completing it alone (e.g. using a mirror) and one saw no barrier to other people doing the same. Clearly, individual experiences, circumstances and capabilities were influential in determining attitudes towards this aspect of skin checking. See Table 3 for further detail. 
Table 3

Quotes reflecting participants' views on family's input into skin checking

\begin{tabular}{|c|c|c|}
\hline $\begin{array}{l}\text { Analysis } \\
\text { overview }\end{array}$ & Quote & Participant \\
\hline $\begin{array}{l}\text { Input of family } \\
\text { to skin } \\
\text { checking }\end{array}$ & $\begin{array}{l}\text { "the bit I can't see is my back, so my husband checks that for me } \\
\text { regularly" }\end{array}$ & $\begin{array}{l}\text { 12035, } \\
\text { female, } 53, \\
\text { Intervention }\end{array}$ \\
\hline $\begin{array}{l}\text { Beliefs about } \\
\text { skin checking } \\
\text { without help }\end{array}$ & $\begin{array}{l}\text { "you definitely can't do it if you're on your own, obviously, you } \\
\text { definite, you need someone" }\end{array}$ & $\begin{array}{l}\text { 11052, } \\
\text { female, } 48, \\
\text { Intervention }\end{array}$ \\
\hline \multirow{2}{*}{$\begin{array}{l}\text { Negative } \\
\text { experience of } \\
\text { skin checking } \\
\text { alone }\end{array}$} & $\begin{array}{l}\text { "I find it extremely difficult because I live in a small house, by } \\
\text { myself," }\end{array}$ & $\begin{array}{l}\text { 11016, } \\
\text { male, } 86, \\
\text { Intervention }\end{array}$ \\
\hline & $\begin{array}{l}\text { "I find quite difficult, well I, well I sometimes don't get that all done } \\
\text { actually, when I'm on my own, no." }\end{array}$ & $\begin{array}{l}\text { 11013, } \\
\text { female } 73, \\
\text { Intervention }\end{array}$ \\
\hline \multirow{2}{*}{$\begin{array}{l}\text { Positive } \\
\text { experience of } \\
\text { skin checking } \\
\text { alone }\end{array}$} & $\begin{array}{l}\text { "the biggest problem is the checking the physical checking of } \\
\text { awkward bits. But, I mean that's really nae the fault of the app but... I } \\
\text { would think most people should manage okay." }\end{array}$ & $\begin{array}{l}\text { 11062, } \\
\text { male 61, } \\
\text { Intervention }\end{array}$ \\
\hline & $\begin{array}{l}\text { "the most difficult is the scalp, because you obviously can't see that, } \\
\text { so but l've got short hair, so it's not too bad, the rest you can pretty } \\
\text { much do yourself, with a mirror." }\end{array}$ & $\begin{array}{l}\text { 11022, } \\
\text { female, } 62 \\
\text { Intervention }\end{array}$ \\
\hline
\end{tabular}

\section{Input of health professionals outside the ASICA trial}

The involvement of health care professionals outside of the trial varied by the demographic and health status of interviewees. Some had been attending scheduled melanoma follow-up appointments in hospital during the study period, others had completed follow-up and had seen only their GP as required, while some had received no health professional contact at all. Participants generally perceived difficulties and barriers to obtaining appointments for their skin in both primary and secondary care. Two interviewees discussed having a lack of confidence in their GP's expertise on skin and corresponding ability to reassure them when concerns arose. Overall, however, around half reported that they were highly satisfied with the care that they were receiving. Around a quarter of participants expressed a preference to receive specialist care rather than care from a GP. See Table 4 below for examples. 
Table 4

Quotes reflecting the role of health professionals in participants' skin monitoring

\begin{tabular}{|c|c|c|}
\hline $\begin{array}{l}\text { Analysis } \\
\text { overview }\end{array}$ & Quote & Participant \\
\hline \multirow{2}{*}{$\begin{array}{l}\text { Variation in } \\
\text { input } \\
\text { from/contact } \\
\text { with health } \\
\text { professionals }\end{array}$} & $\begin{array}{l}\text { "I've got a dermatology appointment and I've got a plastic's } \\
\text { appointment, so it's like run every 3-monthly" }\end{array}$ & $\begin{array}{l}\text { 11052, } \\
\text { female, } 48, \\
\text { Intervention }\end{array}$ \\
\hline & $\begin{array}{l}\text { "they're remarkably busy as, as you would expect and so I was } \\
\text { discharged from dermatology and advised that if I had any concerns } \\
\text { that I would, should see my GP." }\end{array}$ & $\begin{array}{l}11014, \\
\text { female, } 49, \\
\text { Control }\end{array}$ \\
\hline \multirow{3}{*}{$\begin{array}{l}\text { Issues } \\
\text { around } \\
\text { appointments } \\
\text { for skin } \\
\text { health care }\end{array}$} & $\begin{array}{l}\text { "she had to refer me to a GP which, and she, and I had to wait three } \\
\text { weeks to see the GP." }\end{array}$ & $\begin{array}{l}\text { 11013, } \\
\text { female, } 73, \\
\text { Intervention }\end{array}$ \\
\hline & $\begin{array}{l}\text { "it's a week, ten days extra worrying before you find out what it really } \\
\text { is and then, going from there, and then by the time you get an" } \\
\text { appointment for, the scan or whatever, it can, can be months" }\end{array}$ & $\begin{array}{l}11062 \\
\text { male, } 61 \\
\text { Intervention }\end{array}$ \\
\hline & $\begin{array}{l}\text { "was told yeah, I'd be getting a } 6 \text { monthly checks for the next } 5 \text { years, } \\
\text { so I think I had, I'm not sure, it was either, I think after the initial } \\
\text { assessment, it was either 2, possibly 3, certainly no more than 3, and } \\
\text { then there was never any contact made again" }\end{array}$ & $\begin{array}{l}\text { 11040, } \\
\text { male, 51, } \\
\text { Control }\end{array}$ \\
\hline \multirow[t]{2}{*}{$\begin{array}{l}\text { Confidence in } \\
\text { care }\end{array}$} & $\begin{array}{l}\text { "I'm not even always confident that my GP knows what they're } \\
\text { looking for..." }\end{array}$ & $\begin{array}{l}11014, \\
\text { female, } 49, \\
\text { Control }\end{array}$ \\
\hline & $\begin{array}{l}\text { "I think this is new, the GP wouldn't have an idea whether it was new } \\
\text { or wasn't new." }\end{array}$ & $\begin{array}{l}\text { 11022, } \\
\text { female, } 62, \\
\text { Intervention }\end{array}$ \\
\hline $\begin{array}{l}\text { Positive } \\
\text { feedback on } \\
\text { care }\end{array}$ & $\begin{array}{l}\text { "I absolutely cannot ever fault my care, I've been so well looked after, } \\
\text { yeah, no totally, very, very well supported." }\end{array}$ & $\begin{array}{l}\text { 11052, } \\
\text { female, } 48, \\
\text { Intervention }\end{array}$ \\
\hline \multirow[t]{2}{*}{$\begin{array}{l}\text { Preference of } \\
\text { health care } \\
\text { professional }\end{array}$} & $\begin{array}{l}\text { "prefer to speak with the, some kind of professionals, someone like a } \\
\text { dermatologist, than just checking myself, because you know, if you } \\
\text { see your, your body on a daily basis, it's difficult notice that any } \\
\text { changes or something is going on, especially on the back of my } \\
\text { body" }\end{array}$ & $\begin{array}{l}11018 \\
\text { male, } 39 \\
\text { Intervention }\end{array}$ \\
\hline & $\begin{array}{l}\text { "my GP was very dismissive of my mole, and so I probably, if I was } \\
\text { still under the care of the dermatology, I would elect to go direct to, to } \\
\text { dermatology............" }\end{array}$ & $\begin{array}{l}\text { 11048, } \\
\text { Female, } 48, \\
\text { Control }\end{array}$ \\
\hline
\end{tabular}

\section{Ideas around technology}

The sample were relatively experienced in using technology, with over three quarters of participants saying that they used digital devices and apps every day. Most older participants were already familiar with technology and did not perceive a particular it as a barrier to participation since they reported receiving good training at the start of the study. Two participants who were not as keen on using 
technology in healthcare were from the control group, both female, rurally-based and over 70. Both appeared relaxed about their skin and viewed ongoing structured skin-checking and follow-up as potentially burdensome and stressful.

Use of other skin checking apps was rare, and most participants were unaware of their existence. One participant in the control group had used another skin checking app, but found it ineffective, however, using ASICA intrigued them. See Table 5 below for full quote. Previous experience of using digital technology specifically for healthcare was limited within the sample, but there was a general agreement that technology offered promise for more efficient care in the future. One described ASICA as "like a real innovation" (11018, male, 39, Intervention). 
Table 5

Participant experience with and beliefs about technology

$\begin{array}{lll}\begin{array}{l}\text { Analysis } \\ \text { overview }\end{array} & \text { Quote Participant }\end{array}$

Use of apps "Oh gosh, daily, many, many times a day."

11048 ,

female, 48,

Control

"I don't know, I don't know if it's an app or not. Well I mean, I've got two apps on my phone today. One of which works and one doesn't yet."

11017,

female, 76,

Control

"If they are, they'd have been downloaded by my wife, she's the expert!"

11024

male, 76,

Control

Previous experience of health and skin apps "did download something [app to check skin], but it was, it was next to useless,"

"was hoping to be randomised into the group with, with the technology, just because I was interested to, you know, to see what, what that would have been like"

"when I was in hospital the doctor gave me an app, what was it called? Squeezy! Squeezy, or it's called or something. Sort of, pelvic floor exercises."

"Do they, do they actually exist or?"
11048, female, 48, Control
12012, female, 62, Control

11017, female, 76 , Control

11022 , female, 62, Intervention

12035, female, 53, Intervention

"think it's nice as a backup, but when it comes to actually examining moles that could be cancerous I think that still needs to be done by [specialist], when they check me, they're using a specialist eye glass,"

Beliefs about confidentiality
"I'd be more concerned if they hacked into my bank account than into my health."
11022 , female, 62, Intervention

12008 , female, 39, Control
"I wouldn't want any images being stored and easily accessible on my device, so happy if it's all kind of encrypted and locked away by passwords, so that would be a big deal for me in terms of where any data was stored .... no problem with it being uploaded to external storage, but I would have an issue with it being stored locally" 
Participants who had used the ASICA app and participated in the intervention reported few technical problems. Most importantly there did not appear to be any particular issue experienced and associated with a single demographic characteristic. One significant issue was that one participant stated they had not received monthly prompts by text message. (11018, male 39, int). A further two participants reported that some photographs appeared to be missing from their digital skin maps. The hardware provided (Samsung Galaxy tablets) did appear to have created some technical problems with slow functioning and charging difficulties being mentioned. A barrier to use which was identified was the operating system of the tablet. See Table 6 for further details. Another issue expressed was the tablet's camera - a key requirement of ASICA for reporting. Just under a quarter of the intervention group interviewed submitted poor quality photos (reported elsewhere; Murchie et al, in submission), hindering interpretation and assessment of the photographed lesion by the Clinical Nurse Specialist. This then required the submission of further photos, usually from their smartphone to enable the assessment to be completed.

In general, participation in the ASICA trial was viewed positively by most participants. Many expressed their interest in participating as having an altruistic intent, to improve care for others rather than to expect a personal benefit.

There were, however, contrasting views on the direction of influence of technology on health care in the future. Generally, most enthusiasm was expressed by younger participants and those from rural settings. One participant could perceive efficiencies of care, whilst another clearly felt that technology could not substitute for personal fact-to-face care.

Confidentiality and data protection are clearly important considerations when using technology to deliver healthcare although, notably, only one of the interviewees directly volunteered concerns about confidentiality. The concern was around their own device security rather than data misuse. See Table 5 for further details on this.

When asked about the qualities that that effective digital healthcare apps should possess. According to our study, they should be: participants reported coherent and consistent in purpose; straightforward; uncomplicated; and easy to use. It was also said that it is important that apps contain enough information for them to be used effectively and that they signpost the user to further help if needed. 
Table 6

Participant experience of the 'nuts and bolts' of the trial

\begin{tabular}{|c|c|c|}
\hline $\begin{array}{l}\text { Analysis } \\
\text { overview }\end{array}$ & Quote & Participant \\
\hline \multirow{2}{*}{$\begin{array}{l}\text { Feedback } \\
\text { on } \\
\text { operating } \\
\text { system } \\
\text { and } \\
\text { hardware }\end{array}$} & $\begin{array}{l}\text { "I keep forgetting how, because I use Apple, so I keep forgetting how to } \\
\text { turn it on and off, and whatever" }\end{array}$ & $\begin{array}{l}11022, \\
\text { female, } 62, \\
\text { Intervention }\end{array}$ \\
\hline & $\begin{array}{l}\text { "the Samsung app's a bit slow and cumbersome and just not quite up to } \\
\text { speed really is what the ipad is." }\end{array}$ & $\begin{array}{l}11060, \\
\text { male, } 54, \\
\text { Intervention }\end{array}$ \\
\hline \multirow{2}{*}{$\begin{array}{l}\text { Issues } \\
\text { around } \\
\text { the } \\
\text { camera } \\
\text { on the } \\
\text { hardware }\end{array}$} & $\begin{array}{l}\text { "They didn't get a good enough picture using the tablet, and so when, the } \\
\text { guy phoned me back the next day, he said can you use your smart phone } \\
\text { to take a picture, and then send through, because just because the, what } \\
\text { he could see, like l'm not really sure what I'm looking at," }\end{array}$ & $\begin{array}{l}\text { 11052, } \\
\text { female, } 48, \\
\text { Intervention }\end{array}$ \\
\hline & $\begin{array}{l}\text { "when you're trying to take photographs it, it's very difficult to get the } \\
\text { area of skin in focus" }\end{array}$ & $\begin{array}{l}12056, \\
\text { male, } 60, \\
\text { Intervention }\end{array}$ \\
\hline $\begin{array}{l}\text { Problems } \\
\text { in ASICA }\end{array}$ & $\begin{array}{l}\text { "I had is there was one bit where there is no photograph, so I can't for the } \\
\text { life of me think which bit it is now, it was, but there's one bit that I can't } \\
\text { check, because there aren't any photographs, they just keep coming up } \\
\text { blank," }\end{array}$ & $\begin{array}{l}12035, \\
\text { female, } 53, \\
\text { Intervention }\end{array}$ \\
\hline
\end{tabular}

\section{ASICA: impact, design and usability Feelings about using ASICA}

In the ASICA trial, the primary outcomes measured were psychological wellbeing and quality of life measured by the Melanoma Worry Scale (MWS), the Hospital Anxiety and Depression Scale (HADS) and the EQ5-D.[Murchie et al, 2019] A mixture of views were expressed on this point by the users interviewed here. Two participants indicated an initial increase in concern when they began using ASICA but suggested this decreased as they continued to use it. Another participant stated that the app didn't change their worry level but suggested that this may not have been the case if they did not have regular access to specialists as part of ongoing scheduled melanoma follow-up. In contrast, some participants reported finding that they became less anxious when they started using ASICA and were positive about the app enabling people who are likely to worry, the opportunity for greater reassurance compared to less structured alternatives. Importantly it did not seem that the arrival of email or text prompts reminding participants to perform a TSSE led to an increase in anxiety. See Table 7 for full quotes. 
Table 7

The views, experiences and feelings of participants on ASICA

\begin{tabular}{lll|}
$\begin{array}{l}\text { Analysis } \\
\text { overview }\end{array}$ & Quote & Participant \\
\hline $\begin{array}{l}\text { Feelings } \\
\text { induced by } \\
\text { app use: } \\
\text { changes in } \\
\text { worry level. }\end{array}$ & $\begin{array}{l}\text { "It's made me more aware, however, if you were inclined to be } \\
\text { paranoid it's, it's, it's quite scary when you're not medical" }\end{array}$ & $\begin{array}{c}11013, \\
\text { female, } 73,\end{array}$ \\
\cline { 2 - 3 } & $\begin{array}{l}\text { "I was worryention } \\
\text { getting over it a bit, and I think the app maybe just brought it back a } \\
\text { bit" }\end{array}$ & $\begin{array}{l}11054, \\
\text { female, 47, } \\
\text { Intervention }\end{array}$
\end{tabular}

"think having the app kind of brought it back for a while, and I think looking at the pictures didn't really help that, to start with, but I kind of came okay again, with kind of regularly using it"

"I don't worry too much, because I am still under the hospital"

12035 female 53, Intervention

"I think it's very reassuring that you know, if there is something, then you can go back to the pictures, and if you're worried, you can go, you know, it's very, it saves going to your GP if you're worried about this, 11022 , female, 62, have you contacted anybody, so it kind of reminds you to also look Intervention

after yourself, if I can put it that way, and it should make the more anxious, less anxious, but maybe not."

Ideas for improvement of ASICA "you have to watch all the videos before you can just go into actually doing the, the, putting in your data, and that, so and that drives me mad"

"I don't know if there's another format of sharing the, you know, so that they could be zoomed in on or moved or I don't know, they were quite clunky to move around, and find the right bit and they weren't that clear I don't think to look at, they would need, I felt like they needed to be more close up"

"I hate that ruddy bit of kit I'm supposed to sort of keep in communication with you, it's a Samsung thing, I'm an Apple man, so I hate the damn thing, so that gets me frustrated, because I don't understand"
11052 female, 48 , Intervention

11054 female, 47, Intervention

11016 male, 86, Intervention

\section{Semi-structured interview with Dermatology Nurse Practitioner}

The semi-structured interview with the DNP could not be recorded due to technical problems, but field notes are included in Supplementary File S3. Direct quotes were not available due to technical difficulties in recording within Microsoft Teams.in. The interview followed the guide detailed in the methods. Table 8 below records the discussion points and a summary of the response given by the DNP according to field notes produced by FR. 
Overall, the DNP was very positive about the ASICA trial, believing it could reduce workload and be effective as a method of delivering follow-up care for melanoma. He did not think it had increased participants' cancer worries, and indeed felt that for many it had increased their motivation to check their own skin. with the perception of increased participant motivation. The DNP was enthusiastic about the training of Practice Nurses and Advanced Nurse Practitioners located in GP practices however, current levels of training were not viewed as adequate to be allow them to consistently and accurately triage skin lesions. The DNP did have several suggested points of improvement for the ASICA app, which would improve the experience and care provided for patients. Firstly, having the app on patients' own devices or using a more appropriately sized device (i.e. a smartphone rather than a tablet), could reduce the need for participant training and improve image quality. Secondly, the removal of the autozoom feature of the app would improve picture quality. The DNP thought a screening tool to ensure that all images sent to clinicians were of appropriate quality would be a useful addition to the app. Finally, adding a message function enabling messages to be sent directly between the clinician and patient would improve care and reduce follow up work.

\section{Barriers and facilitators to engaging with ASICA}

It appeared that those who had completed follow-up and were no longer receiving regular hospital appointments especially liked using ASICA. One reported that it gave them a sense of 'no-longer being off the radar'. Conversely, one intervention group participant said they relied and engaged less with ASICA after being initially enthusiastic since they still had ready access to a dermatologist and felt they were getting enough input from them. ASICA users also reported that it was more convenient to use the app to submit concerns about their skin rather than having to travel and park at hospital to attend out-patient appointments. There was a sense from some, however, of a certain unwillingness to completely trust the ability of the app to detect something as serious as cancer. This was underlined by another respondent concerned that the validity of ASICA had not been proven due to it being novel and untested. For this individual, the concern was mitigated by the safety net of still being in formal follow-up. The interviews were completed before the COVID-19 pandemic, so it was not possible to determine if experience of the pandemic had an influence on participants' views.

\section{Areas for ASICA improvement}

The layout, design and functionality of the app were generally well-received and only a few participants offered feedback for improvement. The addition of a skip button to prevent the skin checking instructional videos playing in full each time was mentioned by two participants as a time saving measure. Further, the ability to pinch and zoom on skin-map digital photos and clearer orientation was also recommended. The largest area of feedback was that the app should be made available for different operating systems and devices, specifically Apple, so that future users could use the app on their own devices rather than the 7" tablets, which were reported as being awkward to use by some. 
Table 8

The views and experiences of the ASICA dermatology nurse practitioner

\section{Discussion Point Summary of response}

Participants from different sites

Participant Training

Perceptions of individuals who used app more often

ASICA workload
No issues detected. Good contact at Cambridge to liaise.

Training appropriate if problems arose participants sought help from friends or family

No perception of demographic which was more likely to report concern. Had not considered rurality.

Used around half of the time allocated $1 \mathrm{hr}$ per day. Most of the workload generated at weekend.

A direct message function within the app would reduce follow-up workload.

Perceived most work generated by follow up especially the need to request additional images.

Used responsibly and sparingly

Generally used responsibly, a couple of participants used excessively. Mainly due to anxiety and seeking reassurance. Did not perceive that ASICA increased anxiety but rather generally anxious people used it more.

Was used inappropriately as a general skin health tool rather than as specifically for cancer follow up. When prompted this was inappropriate along with some general advice from CNS most seemed receptive.

Was primary site a focus of individuals

Perceived that a small number of participants focused solely on the primary site, but most appeared to do whole body examination.

DNP was more suspicious of new lesions on primary site due to risk of recurrence.

Quality of images submitted

High number of poor-quality images. Believed the autozoom feature of app and the size of the device contributed.

Patient defaults after initial contact

Perceived that there was a high rate of default (i.e. failure to respond to request for further information / images) but wasn't sure why. Felt maybe people were unconcerned, went to their GP or were seen at in person follow up.

CNS felt could be too paternalistic to continuously chase individuals, during trial limited to 2 attempts to contact individuals.

Could a nonspecialist be used in the process

Believes practice nurses could be trained to triage, reassure, flag concerns and refer to a specialist. Believes this could reduce workload. Believed training would need to be algorithmic as pattern recognition a key skill in dermatology

Why was nonspecific benign used rather than a In the instance where this diagnosis was made, DNP felt quite confident it was nothing suspicious however due to lack of information (i.e. clear photos) could not classify further.

specific diagnosis 


\section{Discussion}

\section{Summary of main findings}

This nested qualitative study shows a range of experiences, behaviours, beliefs and feelings amongst people previously treated for melanoma with respect to their skin, skin checking and technology. Most participants stated that they did check their skin regularly, but that using the ASICA intervention increased frequency/consistency of checking and supported a more systematic approach to their skin checking practices. Some ASICA users reported that the intervention improved their confidence about when and how they checked their skin. Few participants managed skin checking alone, and opinions were mixed about the role of health professionals in satisfactory skin checking. Participants in this study, conducted before the onset of the COVID-19 pandemic and its disruptive effect on all aspects of cancer care, were almost universally well-disposed to technology becoming an integral part of their health care, with the caveat that personal interaction can be an element of high-quality care.[Richards et al, 2020] Most saw the potential of digital technology and the likelihood that it will be increasingly used to facilitate healthcare in the future.

Both participants and the study DNP had mainly positive experiences of using the ASICA intervention and made several useful suggestions to improve usability and functionality. The hardware provided, however, was criticised, with several participants reporting issues with the camera and operating system. The hardware (i.e. the tablet) was reported as the main barrier to the ASICA app's use. Most participants did not believe ASICA had changed their feelings around skin checking, but it had raising their awareness and changed their own skin checking behaviours for the better. Overall, using ASICA did not appear to result in adverse psychological effects. Some participants suggested that ASICA had temporarily and briefly increased their anxiety about skin-checking at the start, but that this has settled over time with regular use. In contrast, several participants viewed the app as a means of providing rapid reassurance when concerns arose.

\section{Strengths and limitations}

Nesting qualitative interviews within the main ASICA trial enabled an in-depth exploration of participant beliefs about and experiences with skin checking, use of technology and the ASICA app. It also gave access to participants who were actively thinking about, and engaged with, TSSE and provided qualitative data which will facilitate understanding of the quantitative results of the ASICA trial. Further, the results provide invaluable insights into how digital healthcare is perceived and experienced by these users, which is very important given the likely increasing role of technology to deliver dermatology care in the future NHS This embedded study's sample size of 22 participants represented almost $10 \%$ of the total participants within the ASICA RCT. This sample was purposefully selected to include a range of demographics from two UK sites, with location further assessed to assure representation of both urban and rural participants. This sampling method ensured enhanced representativeness. Including participants from both the intervention and control group enabled a further dimension of understanding 
to the analysis, enabling the attitudes and experiences of those who had, and had not, experienced the intervention to be compared and contrasted.

In contrast, the sample were, on average, relatively well-educated and affluent, with under representation of participants from deprived backgrounds. This is important since individuals from deprived backgrounds are likely to face more challenges in adopting digital healthcare and should be given higher priority for digital healthcare research from now. There is also the possibility of volunteer bias since those agreeing to be interviewed were likely to be interested in technology. This may be reflected in the generally positive tone of the data along with the detailed infrastructural frustrations.

Importantly, there are likely to be differences between participants who did and did not engage fully with the ASICA intervention over the course of the trial. Such differences are both theoretically and clinically relevant, indicating respectively who is least likely to engage with the intervention provided and who is least likely to benefit as a result. It was not possible within the present qualitative study to capture the experiences of those who did not engage fully with the intervention as these participants were the least likely to provide consent to participate in an additional interview. This issue could be explored in future by analysing the TSSE adherence data collected during the ASICA trial to identify the characteristics of those who did not engage.

The interviews were conducted in two tranches by two different interviewers. The transcripts from both sets of interviews were then analysed by a third researcher with support from a senior qualitative researcher and senior clinical researcher. We believe there are limitations, but also strengths in this approach, which has similarities to the accepted practice of secondary analysis of qualitative data.[29] It enabled the data to be considered from different disciplinary perspectives and also provided an objective and consistent interpretation of the written factual data. However, this approach clearly precludes any interpretation based on a recollection of the emotional tone during particular interviews. This limitation was somewhat mitigated by FR spending considerable time to become immersed in the data over three detailed readings. Further, the ongoing involvement of all members of the research team ensured agreement with emerging themes and overall interpretation. The layered approach to the study also acted to reduce individual researcher bias. It was also useful to interview the DNP at the conclusion of the study, after the participant analysis had been completed. By this time, the DNP had had time to reflect on their experience of participating in the trial and on the full range of their interactions with participants throughout. In the context of the responses from ASICA users, this has given quite a clear sense, with respect to ASICA, of what worked well, what did not, and what needs to change.

\section{Context with other literature}

Melanoma follow-up is extensively practiced and, in recent years, has become more important as newer treatments mean that detecting new primaries and recurrences early offers the best outcomes for people ,with melanoma.[30] There is growing evidence on the value of TSSE and how it is perceived and best performed by patients[31] and the ASICA study, including these qualitative data collected in parallel, provides some evidence of the potential future role of digital technology in improving TSSE awareness, 
practice and quality. Several studies demonstrate that there is common anxiety post-melanoma, around attendance at follow up appointments.[32] Our qualitative data consolidate the findings of an earlier qualitative study, which identified structured skin checking as a reassurance technique for those who experienced anxiety following a melanoma diagnosis.[33] These investigators also suggested that low self-confidence about skin checking was a barrier to achieving this benefit, so our respondents' view that ASICA improved their confidence to perform TSSE as very encouraging.[33]. A systematic review of 15 studies further identified reassurance from a qualified professional as reducing worry.[34] This was a finding in the present data too, with participants feeling reassured that a specialist nurse practitioner was reviewing their submitted concerns and images. The added dimension in this study was that anxiety may peak on commencing TSSE (declining thereafter as skin checking becomes more routine), a point which could be borne in mind when developing training and preparing people to undertake TSSE. Travel and distance have previously been recognised as barriers to participating in and benefitting from melanoma follow-up, whereas having a life partner has been cited as an important source of support to successfully completing TSSE.[34,35] Against this context, the positive views expressed by our rural participants are encouraging and support a prevailing view that remote healthcare represents an effective way to meet the challenge of geography in the future. Conversely, our data on the role of partners in assisting with skin checking and the taking of photographs in difficult to see body areas suggest a barrier to TSSE that

technology, and ASICA as currently configured, are not able to address. Interestingly, follow up and melanoma care by GPs was viewed positively in a study in the UK, in contrast to some negative views expressed here.[36] If GP follow-up had been previously viewed as a low-tech solution to the challenge of the increasing melanoma follow-up burden, then, perhaps, ASICA, with its facility of rapid access to a remote dermatology specialist, offers a more elegant solution consistent with the priorities of melanoma survivors themselves. Participants in the present study valued specialist input and the opportunity to contact a specialist between scheduled follow ups. We did not find that age was a barrier to adoption of ASICA, with older users generally reporting that it had been easy to use and that the training prepared them well. This suggests that older people are sufficiently familiar with technology and that the design of ASICA avoids an age-adoption barrier.[37]

\section{Cconclusions And Implications}

This qualitative study embedded with an RCT has provided findings that will complement the main trial findings. With the caveat of some practical issues (mainly relating to a suboptimal digital interface as currently configured), ASICA was positively received by users who found it helpful and that it improved attitudes towards, frequency and thoroughness of TSSE. Some participants reported an initial upswing in anxiety related to using ASICA, but that this subsequently settled over time. The system was effective and was positively viewed in general with some constructive suggestions made for improvement. The study provides important qualitative information that a digital healthcare intervention is an effective means of prompting, recording and responding to structured TSSE by melanoma survivors. Further, it appears that ASICA has potential to offer effective TSSE support to melanoma survivors with a wide range of 
demographic characteristics and could be used to deliver remote support to melanoma survivors across rural and urban areas of the UK.

\section{Declarations}

\section{Ethics approval and consent to participate}

For the ASICA study ethical approval was given by the National Research Ethics Service (NRES) Grampian Ethics committee on 28th April 2017(Reference Number 17/NS/0040), and all participants gave written informed consent. This qualitative sub-study received further ethical approval from the North of Scotland Research Ethics Committee in February 2019 (ref: 17/NS/0040). NHS Grampian Research and Development approved the study in March 2019. All methods were carried out in accordance with Good Clinical Practices and according to the research governance and quality assurance policies and procedures of the University of Aberdeen.

\section{Consent for publication}

Not applicable

\section{Availability of data and materials}

The datasets generated and/or analysed during the current study are not publicly available due to concerns about the potential for individual participants to be identified from the data and due to the scope of the ethical approvals received. However, data may be available from the corresponding author on reasonable request and subject to appropriate safeguards.

\section{Competing interests}

The authors declare that they have no competing interests.

\section{Funding}

The study is supported by a grant from a Cancer Research UK Population Research Committee project award (C10673/A21685). The views and opinions expressed herein are those of the authors and do not necessarily reflect those of Cancer Research UK. The funder (through their peer review and funding board review process) approved the study proposal but had no role in the collection, analysis, or interpretation of data or writing of the report.

\section{Authors' contributions}

PM conceived the study with intellectual contributions from FR, NW, SH, HM, JA and LC. NW and SH conducted the interviews, with project management support from LC. FR analyzed the data with input from PM and HM. PM and FR wrote the manuscript with comments of drafts from NW, SH, HM, JA and LC. 


\section{Acknowledgements}

The authors gratefully acknowledge the time and commitment of those patient participants who gave their time to be interviewed in the study. We also acknowledge the contribution of Billy Brant, Dermatology Nurse Practitioner, NHS Grampian, to the day to day running of the study, for taking part in an interview, and for commenting on the draft manuscript. We acknowledge the support of Andrea Fraser of the ASICA trial team from the Centre of Healthcare Randomized Trials (CHaRT) at the University of Aberdeen. We also acknowledge Hazel Riley who transcribed the interviews for analysis.

\section{References}

1. ICD-10-CM Code C43.9 - Malignant melanoma of skin, unspecified [Internet]. Icd.codes. 2020 [accessed 24 April 2021]. Available from: https://icd.codes/icd10cm/C439

2. Melanoma skin cancer statistics [Internet]. Cancer Research UK. 2020 [accessed 24 April 2021]. Available from: https://www.cancerresearchuk.org/health-professional/cancer-statistics/statisticsby-cancer-type/melanoma-skin-cancer\#heading-Zero

3. Information Services Division NHS National Services Scotland. Cancer in Scotland [Internet]. 2018 [accessed 24 April 2021]. Available from: https://www.isdscotland.org/HealthTopics/Cancer/Cancer-Statistics/Skin

4. Bradford P, Freedman D, Goldstein A, Tucker M. Increased Risk of Second Primary Cancers After a Diagnosis of Melanoma. Archives of Dermatology 2010;146(3).

5. Melanoma skin cancer incidence statistics [Internet]. Cancer Research UK. 2020 [accessed 24 April 2021]. Available from: https://www.cancerresearchuk.org/health-professional/cancerstatistics/statistics-by-cancer-type/melanoma-skin-cancer/incidence\#heading-One

6. Marsden J, Newton-Bishop J, Burrows L, Cook M, Corrie P, Cox N et al. Revised U.K. guidelines for the management of cutaneous melanoma 2010. British Journal of Dermatology 2010;163(2):238-256.

7. Marciano N, Merlin T, Bessen T, Street J. To what extent are current guidelines for cutaneous melanoma follow up based on scientific evidence? International Journal of Clinical Practice 2014;68(6):761-770.

8. Cromwell K, Ross M, Xing Y, Gershenwald J, Royal R, Lucci A et al. Variability in melanoma posttreatment surveillance practices by country and physician specialty. Melanoma Research 2012;22(5):376-385.

9. Francken A, Bastiaannet E, Hoekstra H. Follow-up in patients with localised primary cutaneous melanoma. The Lancet Oncology 2005;6(8):608-621.

10. Berwick M, Begg C, Fine J, Roush G, Barnhill R. Screening for Cutaneous Melanoma by Skin SelfExamination. JNCl Journal of the National Cancer Institute 1996;88(1):17-23.

11. Moore Dalal K, Zhou Q, Panageas K, Brady M, Jaques D, Coit D. Methods of Detection of First Recurrence in Patients with Stage I/II Primary Cutaneous Melanoma After Sentinel Lymph Node Biopsy. Annals of Surgical Oncology 2008;15(8):2206-2214. 
12. Mujumdar U, Hay J, Monroe-Hinds Y, Hummer A, Begg C, Wilcox H et al. Sun protection and skin selfexamination in melanoma survivors. Psycho-Oncology 2009;18(10):1106-1115.

13. The UK: your partner for digital health solutions [Internet]. GOV.UK. 2016 [accessed 24 April 2021]. Available from: https://www.gov.uk/government/publications/digital-health-working-in-partnership

14. Dickinson R, Hall S, Sinclair J, Bond C, Murchie P. Using technology to deliver cancer follow-up: a systematic review. BMC Cancer 2014;14(1).

15. Rollin A, Ridout B, Campbell A. Digital Health in Melanoma Posttreatment Care in Rural and Remote Australia: Systematic Review. Journal of Medical Internet Research 2018;20(9):e11547.

16. Hall S, Murchie P. Can we use technology to encourage self-monitoring by people treated for melanoma? A qualitative exploration of the perceptions of potential recipients. Supportive Care in Cancer 2014;22(6):1663-1671.

17. Murchie P, Allan JL, Brant W, Dennis M, Hall S, Masthoff $\mathrm{J}$, et al. Total skin self-examination at home for people treated for cutaneous melanoma: development and pilot of a digital intervention. BMJ Open [Internet]. 2015 [cited 22 July 2020];5(8):e007993. Available from: http://www.ncbi.nlm.nih.gov/pubmed/26251412

18. Murchie P, Masthoff J, Walter FM, Rahman K, Allan JL, Burrows N, Proby C, Lee AJ, Johnston M, Durrani A, Depasquale I, Brant B, Neilson A, Meredith F, Treweek S, Hall S, McDonald A. Achieving Self-Directed Integrated Cancer Aftercare (ASICA) in melanoma: protocol for a randomised patientfocused pilot trial of delivering the ASICA intervention as a means to earlier detection of recurrent and second primary melanoma. Trials 2019;20:318 https://doi.org/10.1186/s13063-019-3453-x

19. O'Cathain A, Thomas K, Drabble S, Rudolph A, Hewison J. What can qualitative research do for randomised controlled trials? A systematic mapping review. BMJ Open [Internet]. 2013 [cited 22 July 2020];3(6):e002889. Available from: https://pubmed.ncbi.nlm.nih.gov/23794542/

20. Wani, N.M. Murchie, P. Achieving Self-directed Integrated Cancer Aftercare (ASICA) in melanoma: a qualitative study exploring attitudes to app-based technology in melanoma self-monitoring. Unpublished. University of Aberdeen, 2019. (available from Murchie on request: email: p.murchie@abdn.ac.uk)

21. Jin M, Kim J. Development and Evaluation of an Evaluation Tool for Healthcare Smartphone Applications. Telemedicine and e-Health [Internet]. 2015 [cited 22 July 2020];21(10):831-837. Available from: https://pubmed.ncbi.nlm.nih.gov/26431261/

22. Ritchie J, Lewis J. Qualitative research practice: a guide for social science students and researchers. London: Sage; 2003.

23. NVivo qualitative data analysis software; QSR International Pty Ltd. Version 10, 2014

24. Gale N, Heath G, Cameron E, Rashid S, Redwood S. Using the framework method for the analysis of qualitative data in multi-disciplinary health research. BMC Medical Research Methodology 2013;13(1)

25. The Scottish Government (2018) Scottish Government Urban Rural Classification 2016. Available at https://www.gov.scot/publications/scottish-government-urban-rural-classification-2016/ [accessed 
24 April 2021]

26. The Scottish Government (2020) Scottish Index of Multiple Deprivation 2020. Available at https://www.gov.scot/collections/scottish-index-of-multiple-deprivation-2020/ [accessed 24 April 2021]

27. Office for National Statistics (2016). 2011 rural/urban classification. Available at https://www.ons.gov.uk/methodology/geography/geographicalproducts/ruralurbanclassifications [accessed 24 April 2021]

28. UK Government (2019). National Statistics English indices of deprivation 2019. Available at https://www.gov.uk/government/statistics/english-indices-of-deprivation-2019 [accessed 24 April 2021]

29. Long-Sutehall T, Sque M, Addington-Hall J. Secondary analysis of qualitative data: a valuable method for exploring sensitive issues with an elusive population. Journal of Research in Nursing 2010;16(4):335-344. DOI: 10:1177/1744987110381553

30. von Schuckmann LA, Hughes MCB, Ghiasvand R, et al. Risk of Melanoma Recurrence After Diagnosis of a High-Risk Primary Tumor. JAMA Dermatol. 2019;155(6):688-693. doi:10.1001/jamadermatol.2019.0440

31. Bhurosy T, Heckman CJ, Riley M. Prevalence and correlates of skin self-examination behaviors among melanoma survivors: a systematic review, Translational Behavioral Medicine, Volume 10, Issue 5, October 2020, Pages 1120-1133, https://doi.org/10.1093/tbm/ibaa003

32. Rychetnik L, McCaffery K, Morton R, Irwig L. Psychosocial aspects of post-treatment follow-up for stage I/II melanoma: a systematic review of the literature. Psycho-Oncology 2012;22(4):721-736.

33. McLoone J, Watts K, Menzies S, Meiser B, Butow P, Kasparian N. When the Risks Are High. Qualitative Health Research 2012;22(8):1102-1113.

34. Morton R, Rychetnik L, McCaffery K, Thompson J, Irwig L. Patients' perspectives of long-term followup for localised cutaneous melanoma. European Journal of Surgical Oncology (EJSO). 2013;39(3):297-303.

35. Bird J, Coleman P, Danson S. Coping with melanoma-related worry: a qualitative study of the experiences and support needs of patients with malignant melanoma. Journal of Clinical Nursing 2015;24(7-8):937-947.

36. Murchie P, Delaney E, Campbell N, Hannaford P. GP-led melanoma follow-up: views and feelings of patient recipients. Supportive Care in Cancer 2009;18(2):225-233.

37. Berkowsky RW, Sharit J, Czaja SJ. Factors Predicting Decisions About Technology Adoption Among Older Adults. Innov aging [Internet]. 2018 Jan [cited 2019 Apr 24];2(1):igy002. Available from: http://www.ncbi.nlm.nih.gov/pubmed/30480129

\section{Supplementary Files}

This is a list of supplementary files associated with this preprint. Click to download. 
- SupplementaryFile2Framework.docx

- SupplementaryFile1ASICAQualitativeStudyTopicSchedule.docx

- SupplementaryFile3FieldNotesDNPinterview.docx 